\title{
PROFIL PERILAKU MENCARI BANTUAN AKADEMIK (ACADEMIC HELP SEEKING) DITINJAU DARI MASALAH BELAJAR DAN GENDER PADA SISWA SMP NEGERI 3 KOTA BENGKULU
}

\author{
Komang Gangga Swadharma, Hadiwinarto, Vira Afriyati \\ Program Studi Bimbingan dan Konseling Fakultas Keguruan dan Ilmu Pendidikan \\ Universitas Bengkulu \\ gangga.ganteng@gmail.com
}

\begin{abstract}
ABSTRAK
Penelitian ini bertujuan untuk mendeskripsikan profil Academic Help Seeking berdasarkan tingkat dan aspek masalah belajar siswa dan jender. Sampel penelitian adalah siswa kelas VIII SMPN 03 kota bengkulu yang berjumlah 130 orang yang terdiri dari 58 siswa laki-laki dan 72 siswa perempuan. AUM PTSDL untuk mengungkapkan data aspek dan tingkat masalah belajar siswa dan skala academic help seeking untuk mengumpulkan data perilaku mencari bantuan akademik. Data dianalisis dengan menggunakan statistik deskriptif dan komparatif. Hasil penelitian menunjukkan kecendrungan profil perilaku mencari bantuan (academic help seeking) terdistribusi pada aspek Aum PTSDL Perilaku mencari bantuan ada pada setiap aspek masalah belajar tersebut, Kecenderungan profil Academic Help Seeking terdistribusi menurut laki-laki dan perempuan, tidak ada perbedaan academic help seeking ditinjau dari tingkat dan setiap aspek masalah belajar siswa, ada perbedaan academic help seeking yang signifikan antara siswa laki-laki dan perempuan pada semua aspek masalah belajar.
\end{abstract}

Kata kunci: academic help seeking, masalah belajar, jender

\section{PROFILE OF ACADEMIC HELP SEEKING BEHAVIOR REVIEWED FROM LEARNING PROBLEMS AND GENDER IN STUDENT SMP NEGERI 3 KOTA BENGKULU}

\begin{abstract}
This study aims to describe the profile of Academic Help Seeking based on the level and aspects of student learning problems and gender. The sample of this research was students of class VIII SMPN 03 Bengkulu City which consist of 130 students consisting of 58 male students and 72 female students.AUM PTSDL to reveal data aspects and levels of student learning problems and the scale of academic help seeking to collect the data of help seeking academic behavior. Data were analyzed using descriptive and comparative statistics. The results of the study show that: the profile of academic help seeking distributed according to the level and aspects of student learning problems, the profile of academic help seeking was distributed by male and female there is no significant difference in academic help seeking based on the level and every aspect of the student learning problem there is a significant difference of academic help seeking behavior between male and female students on all aspect of student learning problems.
\end{abstract}

Keywords: academic help seeking, learning problem, gender 


\section{Pendahuluan}

Perilaku mencari bantuan (help seeking) merupakan bagian dari regulasi diri berperan penting bagi siswa secara akademik. Pada hakikatnya adalah membantu siswa untuk memperoleh kemampuan untuk belajar mengatur dirinya (selfregulated learning abilities) menjadi tujuan utama dari pendidikan. Academic Help Seeking memungkinkan siswa belajar secara efektif ketika menghadapi kesulitan akademik, dan dapat membantunya untuk memudahkan belajar dengan strategi self-regulated learning (Mark, 2014: 17).Berdasarkan kerangka kerja regulasi diri dalam belajar help seeking merupakan sesuatu strategi adaptif yang digunakan oleh seseorang ketika mereka berusaha mengatasi masalahnya (Newman, 2002). Help Seeking dipertimbangkan adaptif ketika permohonan bantuan dibatasi oleh kebutuhan bantuan untuk mengatasi masalahnya secara mandiri. Siswa mungkin mengalami perbedaan sikap terhadap pencarian bantuan (help seeking) dengan penghargaan pada persepsi keuntungan dan biaya yang dikeluarkan. Peran gender juga adalah harapan sosial yang menentukan bagaimana laki-laki dan perempuan seharusnya berpikir, bertindak, dan merasakan (Santrock, 2008:217).

Menurut Squirl (2017:1) mendefinisikan academic help seeking adalah keterampilan sosial yang memungkinkan individu untuk mengetahui kapan bantuan diperlukan, bagaimana mengakses bantuan secara efektif dengan melibatkan orang lain.Academic help seekingmerupakan suatu strategi regulasi diri penting yang memberi kontribusi terhadap optimalisasi belajar siswa. Suatu keniscayaan bahwa ketika siswa menghadapi kebingungan atau masalah dalam tugas sekolah, pada dasarnya membutuhkan bantuan. Meskipun demikian banyak siswa tidak secara aktif mencari bantuan terhadap pekerjaan akademiknya ketika membutuhkan. Mengapa siswa remaja memutuskan tidak mencari bantuan ketika mereka mengetahui bahwa diriya butuh bantuan? Salah satu karakteristik siswa yang berhubungan dengan perilaku academic help seeking adalah rasa mampu diri secara akademik yang menujukan bahwa dia menilai kemampuan dirinya dapat menyelesaikan tugas-tugas akademik dengan baik dan berhasil. Banyak siswa yang bermasalah belajar memiliki rasa mampu diri yang rendah, mungkin yakin 
bahwa orang lain berpikir bahwa kebutuhan bantuan mengindikasikan bahwa mereka memiliki kemampuan yang kurang dan kurang menyukai untuk mencari bantuan. Sebaliknya, seseorang yang memiliki rasa mampu secara akademik dan tidak memiliki masalah belajar, mereka tidak khawatir bahwa orang lain akan menilai dirinya kurang kemampuan dan mereka lebih merasa nyaman untuk mencari bantuan yang diperlukan.Penelitian ini merumuskan beberapa yang diteliti yaitu sebagai berikut: (1) Bagaimana profil perilaku mencari bantuan akademik (academic help seeking) berdasarkan siswa yang memiliki masalah belajar yang tinggi, sedang dan rendah?, (2)Bagaimana profil perilaku mencari bantuan akademik (academic help seeking) berdasarkan gender pada semua aspek masalah belajar siswa yang tinggi, sedang dan rendah?, (3) Apakah ada perbedaan perilaku mencari bantuan (academic help seeking) berdasarkan masalah belajar yang tinggi, sedang dan rendah ?, dan (4) Apakah terdapat perbedaan perilaku mencari bantuan (academic help seeking) berdasarkan gender?.

Tujuan penelitian ini yaitu sebagai berikut: (1)Untuk mendeskripsikan profil perilaku mencari bantuan akademik siswa berdasarkan masalah belajar siswa yang tinggi, sedang dan rendah, (2)Untuk mendeskripsikan profil perilaku mencari bantuan akademik berdasarkan gender (siswa laki-laki dan siswa perempuan), (3)Untuk mendeskripsikan perbedaan perilaku mencari bantuan (academic help seeking) berdasarkan masalah belajar siswa yang tinggi, sedang dan rendah, (3)Untuk mendeskripsikan perbedaan perilaku mencari bantuan akademik berdasarkan gender (siswa laki-laki dan siswa perempuan), dan (4) Untuk mendeskripsikan perbedaan perilaku mencari bantuan akademik berdasarkan gender (siswa laki-laki dan siswa perempuan).

\section{Metode Penelitian}

Penelitian ini merupakan studi dengan rancangan deskriptif komparatif. Studi deskriptif dimaksudkan untuk mendeskripsikan fenomena-fenomena apa adanya untuk mendeskripsikan fenomena-fenomena apa adanya yang membandingkan dua atau lebih variabel dari dua situasi, kejadian, kegiatan dll yang sejenis atau hampir sama (Sukmadinata, 2010 :72\&79). Dalam penelitian 
ini akan dibandingkan secara empirik variabel Academic Help Seekingberdasarkan masalah belajar siswa tinggi, sedang, dan rendah serta antara laki-laki dan perempuan. Penelitian ini dilaksanakan di Sekolah Menengah Pertama (SMP) 3 Kota Bengkulu.Pelaksanaan penelitian ini dilaksanakan pada semester 2 tepatnya tanggal 19 maret sampai dengan 27 april.

Populasi penelitian ini adalah seluruh Siswa kelas 2 dengan jumlah 202 siswa di SMP Negeri 3 Kota Bengkulu yang terdiri dari 92 siswa laki-laki dan 115 siswa perempuan.Sampel penelitian ini diambil dengan cara purposive random sampling yang merupakan teknik penarikan sampel yang didasarkan pada ciri atau karakteristik yang ditetapkan peneliti sebelumnya dengan strategi mengambil kasus-kasus yang dianggap dapat mewakili populasinya (Dantes, 2012 :46-47). Dalam penelitian ini sampel telah ditentukan peneliti sebelumnya dengan memperhitungkan siswa yang memenuhi kriteria masalah belajar dan siswa yang tidak mengalami masalah belajar melalui data Alat Ungkap Masalah (AUM) PTSDL. Sampel penelitian ini merupakan siswa yang telah mengisi AUM PTSDL pada siswa SMP N 3 Kota Bengkulu di kelas 2 sejumlah 130 siswa yang terdiri dari 58 siswa laki-laki dan 72 siswa perempuan.

Metode pengumpulan data penelitian ini menggunakan kuesioner untuk mengukur variabel Academic Help Seeking menggunakan skala pengukuran 5point, mulai dari 1 = sama sekali tidak mencari bantuan, $2=$ jarang mencari bantuan, 3=kadang-kadang mencari bantuan, 4= Sering mencari bantuan , dan $5=$ selalu mencari bantuan. Siswa dihadapkan pada pernyataan-pernyataan masalah belajar yang dihadapi siswa yang menunjukkan sikap mencari bantuan atau menolak bantuan, kemudian diminta mengisi dengan skala 5 dengan rentang 1 yang berarti tidak sama sekali mencari bantuan sampai dengan 5 yang berarti selalu mencari bantuan jika pernyataannya positif. Jika pertanyaan negatif skor $1=$ mereka mencari bantuan dan skor 5= sangat tidak mencari bantuan.

Untuk menentukan masalah belajar siswa digunakan Alat Ungkap Masalah PTSDL, dengan melihat kualitas kegiatan belajar siswa (Lihat Tabel 1) Pada penelitian ini untuk mengklasifikasi siswa yang memiliki masalah belajar. 


\section{Tabel 1}

Skor ideal dan Kategori Masalah siswa pada AUM PTSDL SMP

\begin{tabular}{|c|c|c|c|c|c|c|}
\hline No & AUM F3 (SMP) & $\begin{array}{c}\text { Jumlah } \\
\text { Item }\end{array}$ & $\begin{array}{l}\text { Skor } \\
\text { Ideal }\end{array}$ & $\begin{array}{c}\text { Kategori } \\
\text { Skor }\end{array}$ & $\begin{array}{l}\text { Mutu } \\
\text { Belajar }\end{array}$ & $\begin{array}{c}\text { Masalah } \\
\text { Belajar }\end{array}$ \\
\hline 1 & Prasyarat penguasaan & 10 & 20 & $\begin{array}{l}15>= \\
10-14=\end{array}$ & $\begin{array}{l}\text { Tinggi } \\
\text { Sedang }\end{array}$ & $\begin{array}{l}\text { Rendah } \\
\text { Sedang }\end{array}$ \\
\hline & Materipelajaran (P) & & & $<10=$ & Rendah & Tinggi \\
\hline 2 & $\begin{array}{l}\text { Keterampilan belajar } \\
\text { (T) }\end{array}$ & 75 & 150 & $\begin{array}{c}112> \\
= \\
75-111= \\
<75=\end{array}$ & $\begin{array}{l}\text { Tinggi } \\
\text { Sedang } \\
\text { Rendah }\end{array}$ & $\begin{array}{l}\text { Rendah } \\
\text { Sedang } \\
\text { Tinggi }\end{array}$ \\
\hline 3 & Sarana Belajar (S) & 10 & 20 & $\begin{array}{l}15>= \\
10-14= \\
<10=\end{array}$ & $\begin{array}{l}\text { Tinggi } \\
\text { Sedang } \\
\text { Rendah }\end{array}$ & $\begin{array}{l}\text { Rendah } \\
\text { Sedang } \\
\text { Tinggi }\end{array}$ \\
\hline 4 & $\begin{array}{l}\text { Diri pribadi siswa } \\
\text { (D) }\end{array}$ & 30 & 60 & $\begin{array}{c}45>= \\
30-44= \\
<30=\end{array}$ & $\begin{array}{l}\text { Tinggi } \\
\text { Sedang } \\
\text { Rendah }\end{array}$ & $\begin{array}{l}\text { Rendah } \\
\text { Sedang } \\
\text { Tinggi }\end{array}$ \\
\hline 5 & $\begin{array}{l}\text { Lingkungan belajar } \\
\text { \&sosio-emosional } \\
\text { (L) }\end{array}$ & 25 & 50 & $\begin{array}{c}37>= \\
25-36= \\
<25=\end{array}$ & $\begin{array}{l}\text { Tinggi } \\
\text { Sedang } \\
\text { Rendah }\end{array}$ & $\begin{array}{l}\text { Rendah } \\
\text { Sedang } \\
\text { Tinggi }\end{array}$ \\
\hline & TOTAL & 145 & 290 & $\begin{array}{c}217>= \\
145-216= \\
<145=\end{array}$ & $\begin{array}{l}\text { Tinggi } \\
\text { Sedang } \\
\text { Rendah }\end{array}$ & $\begin{array}{l}\text { Rendah } \\
\text { Sedang } \\
\text { Tinggi }\end{array}$ \\
\hline
\end{tabular}

Berat ringannya masalah siswa dapat dilihat dari skor kualitas belajar siswa. Kualitas belajar dikategorikan berdasarkan skor kualitas atau mutu belajar siswa dengan mengacu pada skor ideal untuk AUM PTSDL SMP. Siswa dapat dikategorikan memiliki masalah belajar jika kualitas belajarnya ada pada kategori rendah atau kategori masalah belajarnya tinggi. Sebaliknya siswa dikategorikan tidak memiliki masalah belajar apabila kualitas belajar ada pada kategori Tinggi dan masalah belajarnya tergolong rendah.

Untuk menentukan kategori skor Academic Help Seeking digunakan konversi skor (lihat tabel 2). Pada penelitian ini untuk menentukkan kategori pada Tabel 2 menggunakan Skor maksimal ideal (skala 5), mean ideal dan standar 
deviasi sesuai dengan rumus : $\mathrm{Mi}=1 / 2 \mathrm{x}$ Skor maksimal ideal, $\mathrm{Sdi}=1 / 3 \times$ Skor maksimal ideal. (Nurkancana\&Sunartana,1986 : 80).

Tabel 2

Konversi Skor Kategori ideal Academic Help Seeking

\begin{tabular}{lcccccc}
\hline \multicolumn{1}{c}{ KRITERIA } & $\mathrm{P}$ & $\mathrm{T}$ & $\mathrm{S}$ & $\mathrm{D}$ & $\mathrm{L}$ & Total \\
\hline ST (sangat tinggi) & $49>$ & $43,9>$ & $49>$ & $39,95>$ & $49>$ & $225>$ \\
\hline T (Tinggi) & $33-48$ & $27-43$ & $33-48$ & $28-38$ & $33-48$ & $151-225$ \\
\hline S (Sedang) & $16-32$ & $16--26$ & $16-32$ & $14-27$ & $16-32$ & $76-150$ \\
\hline R (Rendah) & $2-15$ & $8-15$ & $2--15$ & $2--13$ & $2--15$ & $2--75$ \\
\hline SR (sangat rendah) & $<2$ & $<8$ & $<2$ & $<2$ & $<1$ & $<1$ \\
\hline
\end{tabular}

Instrumen Skala Academic Help Seeking memiliki Relabilitas dengan Indeks Cronbach Alpha sebesar 0,924 dengan validitas dengan Indeks Corrected Item Total, correlation antara 0,25-0658. Untuk menjawab pertanyaan penelitian menggunakan statistik deskriptif untuk menggambarkan: (1) academic help seeking behavior pada siswa yang memiliki masalah belajar dan mendeskripsikan siswa yang tidak mengalami masalah belajar, (2) academic help seeking behavior pada siswa laki-laki dan perempuan. Untuk menjawab pertanyaan tentang perbedaan academic help seeking antara siswa yang memiliki masalah belajar dan tidak memiliki masalah belajar dan perbedaan help seeking antara siswa laki-laki dengan perempuan dilakukan Uji T-Test Sampel Independent.

\section{Hasil dan Pembahasan}

Deskripsi profil dari masalah belajar berdasarkan Aum PTSDL yaitu Pada masalah belajar siswa terkait dengan prasyarat penguasaan materi pelajaran menunjukkan 88,50 persen pada kategori tinggi dan 11,50 persen berada pada kategori sedang. Pada masalah belajar terkait penguasaan keterampilan belajar menunjukkan 76,90 persen pada kategori tinggi, 19,20 persen berada pada kategori sedang dan 3,80 persen berada pada kategori rendah. Pada masalah belajar siswa terkait dengan sarana belajar menunjukkan 49,80 persen pada kategori tinggi, 50,80 persen pada kateegori sedang dan 3,80 persen berada pada kategori rendah. Pada masalah belajar siswa terkait dengan diri pribadi siswa 
menunjukkan 47,70 persen pada kategori tinggi, 50 persen pada kateegori sedang dan 2,30 persen berada pada kategori rendah. Pada masalah belajar siswa terkait dengan lingkungan belajar dan sosio emosional siswa menunjukkan 97,70 persen pada kategori tinggi dan 23,30 berada pada kategori sedang.

Deskripsi distribusi frekuensi Academic Help seeking(perilaku mencari bantuan akademik) berdasarkan masalah belajar siswa telah terdistibusi sesuai dengan tabel 3 yaitu sebagai berikut :

Tabel 3

Distribusi Frekuensi Academic Help Seeking

\begin{tabular}{|c|c|c|c|c|c|c|}
\hline \multirow{3}{*}{$\begin{array}{c}\text { ACADEMIC HELP } \\
\text { SEEKING }(A H S)\end{array}$} & \multicolumn{6}{|c|}{ Kategori } \\
\hline & \multicolumn{2}{|c|}{ Rendah } & \multicolumn{2}{|c|}{ Sedang } & \multicolumn{2}{|c|}{ Tinggi } \\
\hline & $\mathrm{f}$ & $\%$ & $\mathrm{f}$ & $\%$ & $\mathrm{f}$ & $\%$ \\
\hline AHS terkait masalah P & 0 & $0 \%$ & 37 & $28,50 \%$ & 93 & $71,50 \%$ \\
\hline AHS terkait masalah T & 3 & $2,30 \%$ & 92 & $70,80 \%$ & 35 & $26,90 \%$ \\
\hline AHS terkait masalah S & 10 & $7,70 \%$ & 58 & $52,30 \%$ & 52 & $40 \%$ \\
\hline AHS terkait masalah D & 0 & $0 \%$ & 86 & $66,20 \%$ & 44 & $33,80 \%$ \\
\hline AHS terkait masalah L & 6 & $4,60 \%$ & 70 & $53,80 \%$ & 54 & $41,50 \%$ \\
\hline AHS Total & 0 & $0 \%$ & 77 & $59,20 \%$ & 53 & $40,80 \%$ \\
\hline
\end{tabular}

Tabel 3 menunjukkan distribusi frekuensi academic help seeking siswa terkait pada masalah belajar terdapat dalam kategori rendah, sedang dan tinggi. Pada Academic help seeking (AHS) terkait dengan masalah prasyarat penguasaan materi pelajaran (P) menunjukkan 28,50 persen berada pada kategori sedang, dan 71,50 persen pada kategori tinggi. Pada Academic help seeking (AHS) terkait dengan masalah keterampilan belajar (T) menunjukkan 2,30 persen berada kategori rendah, 70,80 persen berada kategori sedang dan 26,90 persen terletak pada kategori tinggi.Pada Academic help seeking (AHS) terkait dengan masalah sarana belajar (S) menunjukkan $7,70 \%$ berada kategori rendah, 52,30 persen berada kategori sedang dan 40 persen terletak pada kategori tinggi. Pada Academic help seeking (AHS) terkait dengan masalah Diri pribadi (D) menunjukkan 66,20 persen berada pada kategori sedang, dan 33,80 persen pada kategori tinggi. Pada Academic help seeking (AHS) terkait dengan masalah Lingkungan belajar\&sosioemosional(L) menunjukkan 4,60\% berada kategori 
rendah, 53,80 persen berada kategori sedang dan 41,50 persen terletak pada kategori tinggi. Secara total keseluruhan AHS Menunjukkan 53,80\% kategori sedang sedangkan kategori tinggi menujukkan 40,80\% . secara visualisasi tergambarkan pada gambar 1 :

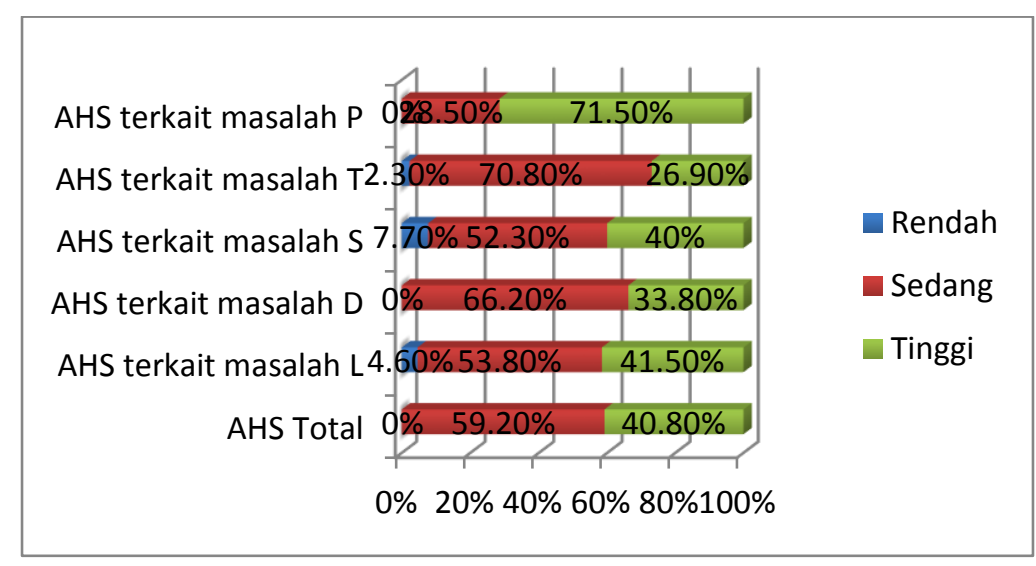

Gambar 1

Profil distribusi Academic Help Seeking (AHS)

Deskripsi academic help seeking berdasarkan laki-laki dan Perempuan dapat dijelaskan bahwa pada siswa laki-laki Academic help seekingdalam masalah $\mathrm{P}$ (Prasyarat penguasaan materi pelajaran) diperoleh nilai mean=33,93(kategori tinggi) dengan standar deviasi=5,4 sedangkan pada siswa perempuan diperoleh nilai mean=36,63(kategori tinggi) dengan standar deviasi=5,2. Pada siswa lakilaki Academic help seekingdalam masalah $\mathrm{T}$ (Keterampilan belajar), diperoleh nilai mean=22,9 (kategori sedang) dengan standar deviasi $=4,15$ sedangkan pada siswa perempuan diperoleh nilai mean= 24,9 (Kategori sedang ). Pada siswa lakilaki Academic help seekingdalam masalah S (Sarana belajar), diperoleh nilai mean=27,9 (kategori sedang) ,sedangkan pada siswa perempuan diperoleh nilai mean= 30,59 (Kategori sedang) dengan. Pada siswa laki-laki Academic help seekingdalam masalah D (Diri Pribadi Siswa), diperoleh nilai mean=23,69 (kategori sedang) sedangkan pada siswa perempuan diperoleh nilai mean $=26,69$ (Kategori sedang ). Pada siswa laki-laki Academic help seekingdalam masalah L (lingkungan belajar dan sosioemosional), diperoleh nilai mean=27,63 (kategori sedang), sedangkan pada siswa perempuan diperoleh nilai mean $=31,77$ (Kategori 
sedang ). Rerata keseluruhan pada siswa laki-laki dan perempuan sejumlah 136,24 pada siswa laki-laki dan 150,65 pada siswa perempuan.

Tabel 4

Uji t variabel Help Seeking pada Masalah Belajar siswa

\begin{tabular}{|c|c|c|c|c|c|c|c|c|c|}
\hline \multirow{2}{*}{$\begin{array}{c}\text { MASALAH } \\
\text { BELAJAR }\end{array}$} & \multicolumn{3}{|c|}{ t } & \multicolumn{3}{|c|}{$\operatorname{Sig} / p$} & \multicolumn{3}{|c|}{ Keterangan } \\
\hline & T-S & R-S & R-T & T-S & R-S & R-T & T-S & R-S & R-T \\
\hline $\mathrm{P}$ & $-0,478$ & & & $0,633(\mathrm{P}>0,05)$ & & & NS & & \\
\hline $\mathrm{T}$ & 1,01 & $-0,119$ & $-0,622$ & $0,315(\mathrm{P}>0,05)$ & $0,906(\mathrm{P}>0,05)$ & $0,536(\mathrm{P}>0,05)$ & NS & NS & NS \\
\hline$S$ & 1,172 & 0,832 & 0,375 & $0,243(P>0,05)$ & $0,408(\mathrm{P}>0,05)$ & 0,709(P>0,05) & NS & NS & NS \\
\hline $\mathrm{D}$ & $-0,117$ & $-0,173$ & $-0,167$ & $0,907(\mathrm{P}>0,05)$ & $0,864(\mathrm{P}>0,05)$ & $0,869(\mathrm{P}>0,05)$ & NS & NS & NS \\
\hline L & $-0,894$ & & & $0,373(\mathrm{P}>0,05)$ & & & NS & & \\
\hline
\end{tabular}

Hasil uji beda menunjukkan academic help seeking antara masalah belajar siswa yang tinggi dan sedang, antara masalah belajar siswa yang sedang dan rendah dan antara masalah belajar siswa yang rendah dan tinggi pada semua aspek masalah belajar diperoleh nilai $\mathrm{t}$ dengan taraf signifikansi lebih besar dari 0,05(P>0,05). Tidak ada perbedaan academic help seeking berdasarkan masalah belajar. Perilaku mencari bantuan akademik (academic help seeking) tidak berbeda berdasarkan masalah belajar siswa, baik siswa yang memiliki masalah belajar tinggi, sedang maupun rendah.

Perbedaan academic help seeking behaviortidak memiliki perbedaan academic help seeking antara siswa laki-laki dan perempuan. Hasil analisis data untuk menguji hipotesis pada tabel 5 :

Tabel 5

Uji t Variabel Help Seeking Berdasarkan Jender

\begin{tabular}{|c|c|c|c|c|c|}
\hline \multirow{2}{*}{$\begin{array}{l}\text { MASALAH } \\
\text { BELAJAR }\end{array}$} & \multicolumn{2}{|c|}{ Mean } & \multirow{2}{*}{$\mathrm{t}$} & \multirow{2}{*}{$\mathrm{Sig} / \mathrm{p}$} & \multirow{2}{*}{ Keterangan } \\
\hline & $\mathrm{L}$ & $\mathrm{P}$ & & & \\
\hline $\mathrm{P}$ & 33,93 & 36,63 & $-2,889$ & $0,005(\mathrm{p}<0,05)$ & Signifikan \\
\hline $\mathrm{T}$ & 22,9 & 24,9 & $-2,624$ & $0,010(\mathrm{p}<0,05)$ & Signifikan \\
\hline $\mathrm{S}$ & 27,79 & 30,59 & $-1,798$ & $0,075(\mathrm{p}<0,05)$ & Signifikan \\
\hline $\mathrm{D}$ & 23,96 & 26,69 & $-3,296$ & $0,01(\mathrm{p}<0,05)$ & Signifikan \\
\hline $\mathrm{L}$ & 27,63 & 31,77 & $-2,793$ & $0,006(\mathrm{p}<0,05)$ & Signifikan \\
\hline
\end{tabular}


Hasil uji beda antara siswa laki-laki dan perempuan diperoleh nilai t secara berturut-turut $\mathrm{P}(\mathrm{t}=-2,889), \mathrm{T}(\mathrm{t}=-2,624), \mathrm{S}(\mathrm{t}=-1,798), \mathrm{D}(\mathrm{t}=-3,296), \mathrm{L}(\mathrm{t}=-2793)$ dengan taraf signifikansi masing-masing lebih kecil dari 0,05 ( $\mathrm{P}<0,05)$. Ada perbedaan mean academic help seeking yang signifikan antara siswa laki-laki dan perempuan. Perilaku mencari bantuan akademik (Academic Help Seeking), pada siswa laki-laki menunjukkan mean lebih kecil dibandingkan siswa perempuan atau siswa perempuan lebih tinggi perilaku mencari bantuan akademiknya daripada anak laki-laki. Jadi siswa perempuan cenderung lebih memilih mencari bantuan akademik ketika memiliki masalah belajar.

Alat ungkap masalah (AUM) PTSDL yang telah diolah dan respondennya terbagi berdasarkan kategori sangat rendah rendah, sedang, dan tinggi. Secara umum, berdasarkan skor yang diperoleh pada AUM siswa dan telah diuji dengan statistik menggambarkan bahwa semua skor telah terdistribusi ke semua aspek kategori dan masalah belajar, sehingga terdapat masalah belajar yang paling dominan dialami oleh siswa yaitu masalah belajar mengenai lingkungan belajar dan sosioemosional siswa (L) yang dilihat pada presentase data menunjukkan pada kategori tinggi anatara lain siswa mengalami permasalahan ketika lingkungan belajar atau sosialnya terganggu seperti ketika ia bertengkar dengan temannya ia tidak mampu didalam belajar. Namun tidak hanya pada masalah" L"saja, melainkan masalah mengenai masalah belajar P,T,S,D mengalami masalah yang tinggi dan ada pula diantaranya yaitu sedang, hal ini dapat dilihat pada tabel hasil statistik deskripsi masalah belajar siswa. Masalah belajar merupakan suatu kondisi di mana anak didik tidak dapat belajar karena adanya ancaman, hambatan atau gangguan dalam belajar (Djamarah, 2010:235). Penelitian ini bertujuan untuk mengidentifikasi permasalahan yang di alami siswa ketika menghadapi masalah atau gangguan belajar dan agar siswa bisa mengentaskan permasalahan yang dialami. Permaslahan-permasalahan yang telah diidentifikasi tidak hanya semata-mata menjadi suatu permasalahan yang belum terentaskan, namun permasalahan yang dialami siswa ini perlu kita lihat sejauh mana siswa tersebut usaha didalam mengentaskan permasalahan yang dalam penelitian ini dilihat perilaku dalam mencari bantuan(Academic Help Seeking 
Perilaku mencari bantuan akademik siswa, tidak begitu bervariasi jika ditinjau dari masalah belajar siswa, tidak ada perbedaan yang signifikan diantara siswa, baik dalam masalah belajar terkait prasyarat penguasaan materi pelajaran (P), Keterampilan belajar (T), Sarana belajar (S), Diri Pribadi (D), maupun Lingkungan belajar dan sosioemosional (L). Ini menunjukkan bahwa perilaku mencari bantuan akademik siswa ada pada setiap aspek masalah belajar siswa. Jika dilihat dari distribusi frekuensi presantase siswa yang mencari bantuan akademik secara keseluruhan siswa pada SMP N 3 Kota Bengkulu terletak pada kategori sedang dan tinggi. Hal ini bermakna bahwa sebagian besar siswa kadangkadang mencari bantuan, dan kurang dari setengah siswa memilki kesadaran untuk mencari bantuan dan jarang mencari bantuan. Sebagian kecil siswa tidak pernah mencari bantuan ketika memiliki masalah belajar. Menurut Gladding (2012:148) ada lima faktor yang mempengaruhi keberhasilan layanan bimbingan dan konseling, dua diantaranya adalah inisiatif dan kualitas daripada klien. Inisiatif ini disebut juga inisiatif untuk berubah. Klien yang enggan adalah seseorang yang dirujuk pihak ketiga seringkali kurang mempunyai motivasi untuk mencari bantuan. Klien yang memiliki inisiatif untuk mencari bantuan akan mudah mencapai keberhasilan layanan bimbingan dan konseling. Berdasarkan hal ini maka bagi siswa yang ada dalam kategori rendah dan sedang atau siswa yang jarang atau tidak pernah mencari bantuan tentu memerlukan layanan bimbingan dan konseling yang memungkinkan klien memiliki inisiatif untuk mencari bantuan. Hal ini menunjukkan kualitas seorang klien yang merupakan faktor lain dari penentu keberhasilan dalam layanan bimbingan dan konseling (Gladding, 2012: 159). Jadi betapa pentingnya kesadaran dan inisiatif untuk mencari bantuan dalam layanan bimbingan dan konseling yang mentukan keberhasilan layanan. Konselor semestinya dapat menangkap isyarat-isyarat apakah seseorang siswa yang datang kepadanya, apakah memiliki niat atau keinginan untuk mencari bantuan secara akademik? Jika belum konselor semestinya dapat menyentuh kesadaran siswa bahwa dirinya memerlukan bantuan.

Pada perempuan memiliki skor yang berbeda secara signifikan dengan siswa laki-laki dalam perilaku mencari bantuan akademik (Academic Help Seeking 
Behavior) pada semua aspek terkait masalah belajar siswa, baik pada masalah prasyarat penguasaan materi pelajaran (P), Keterampilan belajar(T), Sarana Belajar(S), Diri pribadi(D), Lingkungan belajar \& sosioemosional siswa (L) siswa perempuan lebih tinggi skornya dibandingkan dengan skor siswa laki-laki. Hal ini mengkonfrimasi hasil penelitian Ang Lim Tan \& Yau (2004) dan Benenson \& Koulnazarian (2008) yang menemukan bahwa Perempuan umumnya memiliki level yang lebih tinggi dalam perilaku mencari bantuan akademik dibandingkan siswa laki-laki. Kondisi ini juga tidak lepas dari pola asuh siswa perempuan yang membuat dirinya tergantung orang lain.

\section{Kesimpulan dan Saran}

Profil academic help seekingkecenderungannya terdistribusi berdasarkan aspek dan level masalah belajar siswa.Secara keseluruhan skor rerata Academic Help Seeking tidak jauh berbeda pada setiap aspek dan tingkat masalah belajar siswa. Profil perilaku mencari bantuan akademik terdistribusi berdasarkan gender (siswa laki-laki dan perempuan), secara keseluruhan rerata skor academic help seeking perempuan lebih tinggi dibandingkan dengan siswa laki-laki pada setiap aspek masalah belajar siswa.Tidak ada perbedaan academic help seeking yang signifikan antara siswa yang memiliki masalah belajar yang tinggi, sedang, dan rendah pada semua aspek masalah belajar. Ada perbedaan perilaku mencari bantuan akademik (Academic help seeking)yang signifikan antara siswa laki-laki dan perempuan pada semua aspek masalah belajar baik terkait masalah prasyarat penguasaan materi pelajaran $(\mathrm{P})$, masalah Keterampilan belajar(T), masalah Sarana Belajar(S), masalah Diri pribadi(D), masalah Lingkungan belajar \& sosioemosional siswa (L). Pelayanan bimbingan dan konseling agar lebih efektif guru BK penting mengenali level academic help seeking siswa baik yang tinggi, sedang maupun rendah. Academic help seeking yang sedang dan rendah pada siswa penting menjadi perhatian untuk mengantisipasi kemungkinan keberhasilan siswa dalam menjalani layanan bimbingan dan konseling. Secara umum siswa yang memiliki academic help seekingyang tinggi memiliki kecendrungan mencari bantuan dalam setiap masalah siswa yang dihadapi patut mendapat perhatian 
karena memiliki potensi keberhasilan dalam layanan bimbingan dan konseling. Program bimbingan dan konseling sudah semestinya mempertimbangkan berbagai aspek masalah belajar siswa dan perilaku mencari bantuan akademik (academic help seeking) agar implementasi program dapat berjalan dengan efektif. Perbedaan perilaku academic help seekingantara siswa laki-laki dan perempuan ini menunjukkan bahwa dalam pemberian layanan bimbingan dan konseling patut mempertimbangkan pelayanan yang memandirikan siswa agar memiliki inisiatif untuk berubah pada siswa laki-laki dan perempuan dapat mencari bantuan ketika diperlukan.

\section{Daftar Pustaka}

Ang, R. P., Lim, K. M., Tan, A. \& Yau, T. Y. (2004). Effects of gender and sex role orientation on help-seeking attitudes. Current Psychology, 23, 203214.

Benenson, J.F. \& Koulnazarian, M. (2008). Sex differences in help-seeking appear in early childhood. British Journal of Developmental Psychology, 26, 163167.

Dantes, N. (2012). Metode Penelitian. Yogyakarta : Andi Offset

Djamarah, B.S, (2008). Psikologi Belajar. Jakarta.Rineka Cipta.

Gladding, Samuel T. (2012). Konseling Profesi yang Menyeluruh. Jakarta: Indeks Mark.Ng, (2014). Self-efficacy beliefs and academic help seeking behavior of Chinese students. Journal of Educational Sciences \& Psychology, Vol.IV (LXVI) No.1, 17-31

Newman, R.S (2002). How self-regulated learners cope with academic difficulty: The role of adaptive help seeking. Theory into Practice, 41(2), 132-138

Nurkancana,W, Sunartana, P.N, (1986). Evaluasi Pendidikan. Surabaya : UsahaNasional.

Prayitno (2004). Aplikasi Instrumentasi . Padang : Universitas Negeri Padang

Santrock, J.W. (2008). Psikologi Pendidikan (Edisi Ketiga) Jakarta: Penerbit Salemba Humanika.

Sukmadinata, Syaodih, Nana. (2010). Metodologi Penelitian pendidikan. Bandung. Remaja Rosda Karya. 
Swadharma, Hadiwinarto, Afriyati

Squirl, Karl, L.(2017). Help Seeking.di akses dari Excellence In School Counseling Hal 1-4 Tanggal 20 Maret 2017. 